\title{
The Relationship between Hamstring Flexibility and Level of Competitive Irish Dancers
}

\author{
Rosalia Motta ${ }^{\mathrm{a}}$ Patricia Talarczyk ${ }^{\mathrm{a}}$
}

The purpose of this study was to investigate the potential relationship between hamstring flexibility and competitive level of Irish dancers. Since the premier of Riverdance in 1994, Irish dance has grown in population and has geologically spread to locations previously unassociated with Irish culture. Resulting from these changes has been the establishment of more and larger competitions, as well as increased athleticism in the dance form. This study followed a quasi-experimental approach, and dancers volunteered to participate. Participants were first asked verbal questions for secondary data collection and data on performance level. Hamstring flexibility was then measured using the Straight Leg Raise (SLR) test for analysis. The data support the conclusion that higher level Irish dancers have higher hamstring flexibility than lower level dancers. Irish dancers seeking to advance into higher competition levels may use this information to incorporate more flexibility building into their training. Likewise, Irish dance instructors may devote more instruction time to assisting their students in building their hamstring flexibility efficiently and properly. Future researchers may investigate similar studies with other physical aspects, such as flexibility in the quadriceps. Alternatively, researchers may investigate the extent to which Irish dance adjudicators seek out high hamstring flexibility in the dancers they judge in comparison to more traditional aspects of Irish dance.

Keywords: Hamstring flexibility, Irish dance

Research regarding dance has spanned over countless varying dance genres with numerous topics of inquiry. Irish dance is just one such genre that has been studied, and while research that has so far been completed on this dance type has been relatively limited in comparison to more prominent dance forms, more focus has been placed on Irish dance research in recent years. Irish dance seems to be gaining momentum over time; it was once primarily practiced only by those with secure connections to Ireland but has since extended to countries previously unassociated with Irish culture, such as Argentina and China. The overriding source of this change was seemingly the debut of Riverdance in 1994, a popular show integrating distinct dance types with a heavy emphasis on Irish dance (Masero, 2010). The direct impacts of the Riverdance premier on the popularity of Irish dance can be observed through the geological spread of Irish dance as well as a drastic increase in attendance at worldwide Irish dancing events. As a result of the heightening popularity of Irish dance in recent decades, more research is necessary in order to identify aspects important to competitive readiness and success in Irish dance.

The increasing popularity of Irish dance has instigated more and larger competitions. The annual World Championships is held by A Coimisiún le Rincí Gaelacha (CLRG), translated from Irish Gaelic to "the Irish Dancing Commission," which is the largest governing body of Irish dance. According to Olivia Steffan, between the years of 1988 and 2014, the number of participants at the World Championships increased by $68 \%$. Most of the observed attendance growth occurred following the introduction of Riverdance in 1994, as well as the first tour of the show in 1995. In addition to the increase in competitors, the location of the World Championships has also spread; the World Championships took place in Philadelphia in 2009, which was the first time the competition was held outside of Great Britain or Ireland since its introduction in 1970 (2014). Perhaps in response to elevated competition, Irish dance has grown progressively athletic in nature, similarly to trends previously noted with other dance forms; larger movements caused by increased athleticism create more dramatic effects while dancing (Keay, 1998). Specifically, Irish dance has become more acrobatic, demanding exaggerated technique and intensified power (Masero, 2010). Hamstring flexibility enables dancers and other athletes to perform high kicks without strain and can therefore be considered an indication of athleticism. This study will focus on observing the potential relationship between a physical aspect, hamstring flexibility, on the competitive level of female Irish dancers.

Flexibility in the hamstrings is a critical aspect of certain dance forms, including ballet and contemporary dance. Flexibility, synonymous with the term "muscle length," increases range of motion in the joints. Currently, it is unknown how important, if at all, hamstring flexibility is to Irish dance specifically; however, due to the steady growth of athleticism in Irish dance, there is a possibility that hamstring muscle length connects to competitive success in Irish dance. The notion that hamstring flexibility increases with competitiveness in other dance genres has been supported by several studies. For example, Bruna Martinez and her team found competitive ballet dancers to have overall higher hamstring flexibility than recreational ballet dancers (Martinez, Curtolo, Lucato, \& Yi, 2014). My study was created upon the hypothesis that Irish dance would share a similar trend, with more advanced levels or "more competitive" dancers having higher hamstring flexibility overall than those in lower competition levels.

Several studies have suggested a connection between hamstring flexibility and tendency to develop muscle injuries in various populations of athletes. For instance, the author of a study involving several different dance forms identified muscle inflexibility as a common but treatable cause of injury in dancers in general (Russell, 2013). Another study focused specifically on flexibility in the hamstrings and quadriceps, but in soccer players rather than dancers. The authors reached the conclusion that inflexibility in these muscle groups is a definite cause for injury in these athletes (Witvrouw, Danneels, Asselman, D'Have, \& Cambier, 2003). Although not directly related to the topic at hand, muscle injuries, which include muscle pulls, tears, and strains, can hinder the

a. Mentor High School, Mentor, OH, 44060 
performances of dancers due to pain and recovery time. For this reason, secondary data will also be completed focusing on the relationship between hamstring flexibility and muscle injury occurrence.

Certain injuries are more common in dancers than other injuries, and injury occurrence further fluctuates along with dance genre. Within a study sample of a few contrasting dance types, with the inclusion of Irish dance, leg injuries were much more common than arm injuries (Russell, 2013). Although dance forms in general have provoked higher occurrences in leg injuries than arm injuries, studies solely encompassing Irish dancers have identified even further discrepancies between injuries in the two areas of the body. A study completed by Cynthia Stein and her team found that about $96 \%$ of the participants, all of which were Irish dancers, had recently suffered from injuries in the lower extremities, the area from the hips to the ankles. Approximately $8 \%$ of the reported injuries were muscle injuries specifically (Stein et al., 2013). Another study shared similar findings, with sixty-nine female Irish dancers reporting 217 injuries total, 95\% of which occurring in the lower extremities (Noon, Hoch, McNamara, \& Schimke, 2010). Competitive Irish dancers do not utilize any upper body movement while dancing, causing the lower extremities to be particularly susceptible to injury; as a result, precautions need to be taken in order to avoid injury. Adequate flexibility in muscles, particularly the hamstrings, can prevent strains and other common muscle injuries, especially in populations such as Irish dancers, who are prone to leg injuries.

Under CLRG, groups may hold smaller Irish dance competitions known as feiseanna. Dancers' levels depend on attendance and results at these feiseanna rather than competitions such as the World Championships that are held directly by the Irish Dancing Commission. Regional councils and authorities identified by CLRG are responsible for ensuring that respective committees running each feis are complying entirely with the rules of CLRG. An example of such an authority is the Irish Dance Teachers' Association of North America (IDTANA), and such bodies confirm that groups organizing feiseanna are satisfactory in both professionalism and efficiency ("Rules for Regional Councils," 1996).

Although various associations and committees may organize feiseanna, certain guidelines have been set by regional authorities, allowing competition levels to remain constant between feiseanna under each given council. All committees running North American feiseanna under the Irish Dancing Commission must first register the competitions through the North American Feis Commission in order to be recognized by the NAFC and, by extension, CLRG ("Dancing Competition Rules," 2015). The NAFC has established six levels at feiseanna; the two most advanced levels are considered "championship" levels, whereas the other four levels are considered "grade" levels. The first level, which consists only of Irish dancers who have been taking lessons for less than one year, is Beginner, followed by Advanced Beginner, Novice, Prizewinner, Preliminary Championship, and finally Open Championship ("Mid-America Standardized Syllabus," 2017). These six levels will be critical in the evaluation of data in this study.

In North America, certain criteria for advancement into a subsequent level has been established by the NAFC, but other criteria instead depends on the region in which the dancer resides. For instance, the North American Feis Commission syllabus mandates that Preliminary Championship dancers qualify for Open Championship after winning no less than two Preliminary Championship competitions (2015). The NAFC requires a minimum amount of first place wins, two, before granting a dancer with Open Championship status, allowing the Mid-Atlantic region to devise a rule requiring three Preliminary Championship wins ("MidAtlantic Regional Syllabus," 2006). The NAFC therefore sets minimum requirements for level advancement, but regions can extend such mandations further.

The following criteria was established within the 2017 Mid-America syllabus regarding advancement into higher competitive levels. The Mid-America syllabus was chosen as a result of being the region that most participants within this study resided in. All feiseanna held in the Mid-America region are required to follow such rules stated in the region's syllabus. Advanced Beginner dancers who obtain a first, second, or third place finish in a particular dance will advance to the Novice grade in that respective category. The different dances competed at competition are distinct from each other in that they represent different styles, with the music played at assigned tempos. A first-place finish in the Novice grade then advances a dancer to the Prizewinner grade in the dance that earned him or her the win. In order to qualify for the Preliminary Championship level, a dancer must earn a first place in each of the four Prizewinner dances, which are further explained within the syllabus. At this point, however, the dancer is only eligible to advance into Preliminary Championship with the consent of the registered Irish dance instructor (2017).

Beyond qualifications, several differences exist between the competition levels. Dancers typically compete with more complicated, intricate choreography as they transcend into higher levels. The first four levels, Beginner through Prizewinner, are judged by a single adjudicator, whereas competitions within the two championship levels are scored by at least three adjudicators ("Dancing Competition Rules," 2015). Rather than being a full indication of skill level, the only difference between the Beginner and Advanced Beginner levels are that dancers within the Advanced Beginner category have participated in Irish dance lessons for over one year. As a result, for the purposes of this study, Beginner and Advanced Beginner dancers will be the same level. Beyond the differentiation between Beginner and Advanced Beginner levels, which relies solely on the amount of time an individual has been enrolled in Irish dance classes, subsequent levels depend only on competitive performance and achievement in lower levels.

The amount that choreography increases in intricacy along with level advancement is best shown through the tempos required for the different dances. The Mid-America syllabus lists the various tempos, which change in correspondence with level. For instance, one dance, the reel, is danced to music set to a tempo of 122 beats per minute for Beginner, Advanced Beginner, and Novice dancers. Reels are then played at a slower tempo of 113 beats per minute for Prizewinner, Preliminary Championship, and Open Championship competitions, allowing for the completion of more complicated choreography at a reasonable speed. Two other dances, treble jig and hornpipe, are not danced until the Advanced Beginner grade, in which treble jig music is played at 92 beats per minute and hornpipe music is played at 138 beats per minute. Much slower tempos are established for both of these dances beginning in Novice: 73 beats per minute for treble jig and 113 beats per minute for hornpipe. Both Novice and Prizewinner dancers 
can choose which of the two tempos to dance at during feiseanna depending on the choreography provided by their Irish dance teachers ("Mid-America Standardized Syllabus," 2017).

\section{Experimental Procedures}

The selected method was quasi-experimental, and this particular approach was chosen as dancers could be separated into distinct groups based on their competition levels. Since the levels are predetermined and cannot be altered by a researcher, a quasiexperimental classification was the most suitable for this study. I completed data collection at two single-day feiseanna after obtaining permission from both committees running the competitions. Dancers competing at these two events volunteered for the study if interested. I sought to simply acquire as much participation as possible. Due to a relatively low population of male Irish dancers and contrasts in muscle length tendencies in relation to females, only female dancers were involved in this study. After collecting data at the two competitions, I attended a performance class targeted towards the non-championship levels at a local Irish dance academy. Most of the non-championship dancers who participated were attendees at this class.

A study involving human participants first required approval from the Institutional Review Board. I was able to acquire endorsement prior to collecting data. In order to retain confidentiality, each dancer who participated was identified within my data table as "Dancer 1," "Dancer 2," and so on, simply depending on participation order. At the feiseanna I attended, after obtaining the necessary assent or consent from dancers and their parents, I verbally asked each participant a few questions to be used for both primary and secondary data collection. These questions included the participant's current age in years, her current competition level, whether she had suffered from any muscle injuries in the past six months, and the estimated amount of days she practices Irish dance weekly. I immediately wrote down all responses to these questions, adjacent to the dancer's assigned number. For clarification, "current competitive level" was defined as the level in which she competed in at that particular feis even if she was qualified for a higher level. When inquiring about muscle injuries, I stated that such a term encompassed any strains, pulls, and tears in any muscle. I also emphasized that the average practice days should include both individual practice and instruction-based practice, but practice in other physical activities was to be excluded. In certain instances, the dancers provided a range of days they practice every week. In such cases, I wrote the exact range provided. I then measured the hamstring flexibility of the participant using the Straight Leg Raise test.

The Straight Leg Raise test (SLR test) is a passive examination used to assess hamstring flexibility and is often utilized in clinical settings. The participant remains entirely relaxed throughout the test. The SLR test requires the participant to lie on their back with both knees completely extended. I raised the leg being tested as far as possible without a bend in either knee. I asked the participant to notify me once she felt she was unable to raise her leg further. This signifies the maximum hamstring flexibility of the participant; at this point, the participant should feel a slight strain but no pain. I asked each participant to inform me if she felt pain in the hamstring muscle during the completion of the SLR test. Once the participant notified me of being unable to raise her leg further, I asked an assistant to hold the ankle of the measured leg in order to retain its position. The angle formed bet ween the legs of the participant, designated in this test as the SLR angle, was measured to the nearest degree using a twelve-inch goniometer, an angle-measuring device commonly utilized in physical therapy settings to assess range of motion. After measuring the right leg of each participant, I then measured the left leg.

The SLR angles I determined for each participant were written next to the responses to each of the verbal questions. The full raw data, including responses to the verbal questions and Straight Leg Raise angles for each participant, can be found in the Appendix. Figure 1 shows one participant, a Preliminary Championship dancer whose right SLR angle was well above the average with a measure of 156 degrees. Figure 2 presents another Preliminary Championship dancer who was considerably less flexible, with a measured right angle of 105 degrees.

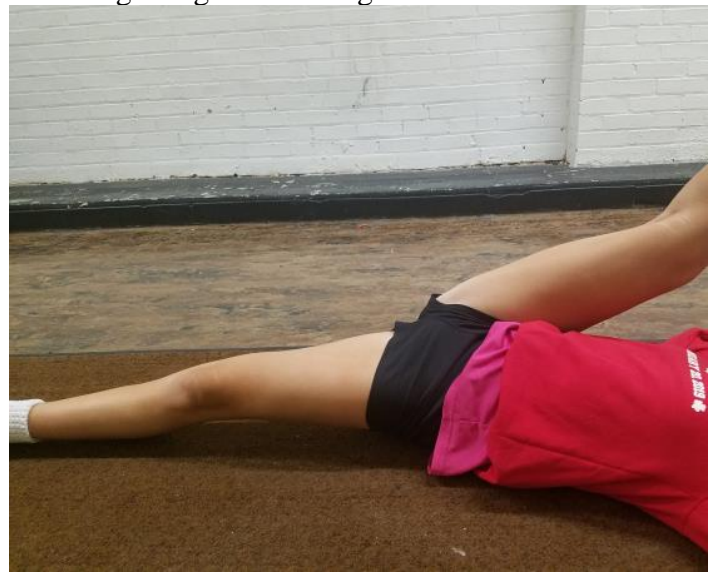

Figure 1. Participant with SLR angle of 156 degrees. 


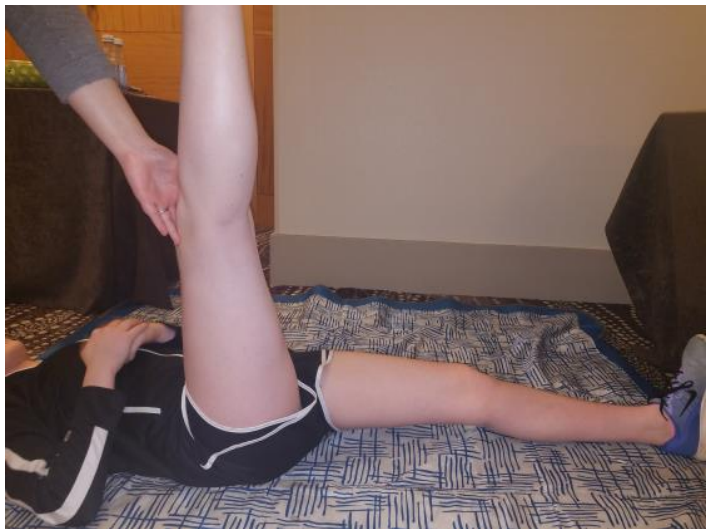

Figure 2. Participant with SLR angle of 105 degrees.

The Straight Leg Raise test was used in this study primarily as a result of its significant reliability. Prior to selecting the SLR test, I had researched various possibilities for hamstring flexibility evaluation methods. Scott Davis and his team measured the concurrent reliabilities of four different hamstring flexibility tests, which included the SLR test. They concluded based on the results that each of these four tests could be deemed reliable (Davis et al., 2008). An alternate hamstring flexibility test contemplated for this study was the Active Knee Extension (AKE) test. However, using this examination, if the participant's flexibility surpasses a certain amount, the flexibility simply cannot be measured further. The AKE test essentially only measures flexibility to the equivalent of what would be ninety degrees using the SLR test. Once the benchmark is reached using the AKE test, there is no observing exactly how much the participant can surpass that amount. The SLR test, on the other hand, sufficiently measures a much wider range of flexibility measurements (Cameron \& Bohannon, 1993). As a result, the Straight Leg Raise test was used instead of the Active Knee Extension.

Despite being a reliable flexibility test, some aspects of the SLR test required clarification and supervision. For instance, in order to maintain consistent measurements, participants were asked not to flex their ankles, since ankle dorsiflexion can decrease the angle measured during the Straight Leg Raise test by shortening the hamstring muscle (Boland \& Adams, 2000). Additionally, complete knee extension is critical to proper results from the SLR test. Cameron and Bohannon determined that a limitation of the SLR test is that participants tend to find difficulty in maintaining full extension throughout the test (Cameron \& Bohannon, 1993). As a result, I first asked participants to extend their knees; throughout the test, I then ensured their knees remained straightened. I measured the both legs of each participant, and the measurements were later averaged. Beforehand, I asked each participant to ensure they were a bit warmed up and stretched out in order to avoid injury and misleading tightness in the hamstrings, which would have falsely decreased the SLR angle measured. Participants, however, were not required to follow identical warm up procedures; since I was the sole individual measuring the Straight Leg Raise angles of each participant, I would have been unable to oversee such procedures throughout data collection. Dancers were trusted to have efficiently warmed up in preparation for the competition but were simply asked to do so just in case. All flexibility measurements and responses to the verbal questions were added to a data table following the conclusion of each competition I attended for data collection.

In order to determine the extent of statistical significance shown by the results, a one-way analysis of variance (ANOVA) was completed. The ANOVA was selected as a result of there being at least three independent groups in this study.

\section{Results}

The total number of participants reached 61 with ages ranging from six to thirty-eight years. Of the 61 dancers who participated, 33 competed in one of the two championship levels. Only four dancers reported having a muscle injury in the past six months. One dancer was removed from the data set entirely due to an injury interfering with the ability to fully extend the knee and thus accurately complete the flexibility test, leaving the total amount of participants included in the data at 60 .

\section{Descriptive Statistics}

Table 1 shows the number of participants within each competition level (N), as well as the mean value of the SLR angle for each participant and standard deviation (SD). The right and left SLR angles were averaged for each individual participant in order to obtain a collective angle for the right and left legs. The average angles per dancer were then used to determine the average angle per level.

\section{Table 1}

Descriptive Statistics for SLR Angle of Each Level

\begin{tabular}{|llll|}
\hline Level & $N$ & Mean & $S D$ \\
\hline Open Championship & 11 & 115.55 & 15.59
\end{tabular}




\begin{tabular}{|c|c|c|c|}
\hline Preliminary Championship & 21 & 123.90 & 16.90 \\
\hline Prizewinner & 13 & 104.04 & 14.79 \\
\hline Novice & 10 & 105.60 & 17.87 \\
\hline $\begin{array}{l}\text { Beginner/Advanced } \\
\text { Beginner }\end{array}$ & 5 & 103.00 & 9.90 \\
\hline Total & 60 & 113.28 & 17.80 \\
\hline \multicolumn{4}{|c|}{$\begin{array}{l}\text { Note. One Open Championship dancer suffered from a knee injury at the time of data collection and therefore was only able to } \\
\text { complete the SLR test with one leg. This dancer is therefore not included in the table. }\end{array}$} \\
\hline \multicolumn{4}{|c|}{$\begin{array}{l}\text { Statistical Significance } \\
\text { In preparation for the ANOVA, the levels were first separated into three distinct groups: A "championship" group, a } \\
\text { "intermediate" group, and a "beginner" group. The championship group encompassed dancers competing within the highest tw } \\
\text { competition levels, Open Championship and Preliminary Championship. The intermediate group contained dancers in the next tw } \\
\text { levels, Prizewinner and Novice. The beginner group included Advanced Beginner and Beginner dancers. Table } 2 \text { demonstrates th } \\
\text { updated descriptive statistics of each competition group that was established in preparation for the Analysis of Variance. }\end{array}$} \\
\hline \multicolumn{4}{|l|}{ Table 2} \\
\hline \multicolumn{4}{|c|}{ Descriptive Statistics for SLR Angle of Each Competition Group } \\
\hline Level & $N$ & Mean & $S D$ \\
\hline Championship & 33 & 121.03 & 16.70 \\
\hline Intermediate & 23 & 104.72 & 15.83 \\
\hline Beginner & 5 & 103.00 & 9.90 \\
\hline Total & 60 & 113.28 & 17.80 \\
\hline
\end{tabular}

Using the competition groups established in Table 2, a One-Way Analysis of Variance was completed (SocSciStatistics, 2019). The results of the ANOVA are depicted in Table 3. A p-value of .0008 was obtained, indicating high statistical significance at $\mathrm{p}<.001$. Such a low calculated $\mathrm{p}$-value demonstrates that the data is highly inconsistent with the null hypothesis that there is no relationship between hamstring flexibility and the level of competitive Irish dancers. As a result of the high statistical significance, with a high degree of confidence, the null hypothesis was rejected.

\section{Table 3}

One-Way Analysis of Variance of SLR Angle by Competition Group

\begin{tabular}{|lccccc|}
\hline Source & $S S$ & $d f$ & $M S$ & $F$ & $p$ \\
\hline Between groups & 33 & 2 & 2068.67 & 8.10 & .0008 \\
Within groups & 23 & 57 & 255.30 & & \\
Total & 60 & 59 & & & \\
\hline
\end{tabular}

Note. Data statistically significant at $\mathrm{p}<.001$. 
The ANOVA test indicated a high degree of inconsistency with the null hypothesis; thus, the data supports the notion that there is a relationship between hamstring flexibility and the level of competitive Irish dancers, and the hamstring flexibility increases in correspondence with higher levels.

As briefly stated, only four of the sixty participants reported suffering from a muscle injury within the previous six months. With such a low number of reported injuries, the intended secondary analysis on muscle injuries in relation to hamstring flexibility remained inconclusive.

\section{Limitations}

There were several limitations within this study. For instance, I did not receive professional training regarding how to accurately measure the SLR angle and thus properly complete the Straight Leg Raise flexibility test. As a result, my perceptions over whether the goniometer utilized to measure the angle was properly aligned with the legs of the participants may have differed from that of a professional, such as a physical therapist. However, because I was the only individual to measure the SLR angles, alignment perceptions remained consistent throughout the data collection process, which limited the potential impact of the lack of professional training.

An additional limitation that emerged from the study was a relatively small population sample. Over half of the total amount of participants were dancers competing within one of the highest two levels, Open Championship and Preliminary Championship. On the other hand, even after combining the Advanced Beginner and Beginner levels into a single group, by the end of data collection, only five dancers within these levels were measured and consequently recorded in the data. The population sample for the beginner group specifically was very low, and there is a high possibility that more accurate results could have been yielded with a larger population sample.

\section{Discussion}

The original hypothesis was devised based upon current understanding in the body of knowledge. One of the most influential sources in constructing the hypothesis was a study completed by Bruna Martinez and her research team. Based on their results, they concluded that competitive ballet dancers tend to have higher hamstring flexibility than recreational ballet dancers (Martinez, Curtolo, Lucato, \& Yi, 2014). Combining their findings with current knowledge surrounding the evolving nature of Irish dance, as shown through the noted increased athleticism of the sport, I hypothesized that higher-leveled Irish dancers would, overall, exhibit higher hamstring flexibility than Irish dancers within lower levels. Ultimately, the data supported the aforementioned hypothesis and this study therefore connects strongly to the current existing literature.

Previous studies have determined Irish dance to be becoming increasingly acrobatic in nature, as demonstrated by overemphasized technique and high kicks while dancing (Masero, 2010). Hamstring flexibility, the main influence enabling athletes to perform high kicks, was suggested to be influential in competitive Irish dance through the analysis of this study. The observed heightened athleticism has been even further substantiated with the support of the hypothesis that higher level Irish dancers would have higher flexibility than lower level dancers. Additionally, as it has already been established that hamstring flexibility is influential in dance forms such as ballet and contemporary dance, this study demonstrates yet another dance genre in which hamstring flexibility may be significant.

The analyzed results of this research provide specific implications, particularly to those directly involved with Irish dance, such as competitors and their instructors. In relation to the findings of this study, competitive Irish dancers seeking to advance into higher levels at feiseanna may incorporate larger amounts of flexibility building into their training. The findings do not necessarily imply causation, so currently, it remains unseen whether hamstring flexibility causes dancers to reach higher competitive levels. However, with a strong suggestion of a positive relationship between flexibility and level, Irish dance instructors may devote an increased amount of instruction time to assisting their students, the dancers, in enhancing their flexibility efficiently and properly.

These findings present several potential research topics in the future. In terms of Irish dance research, researchers may decide to investigate whether other physical aspects similarly relate to level or success in competitive Irish dance. Researched physical components may include flexibility or range of motion of other muscle groups, such as the quadriceps or hip flexors, depending on the extent to which these alternative physical components are influential in other dance forms. Alternatively, researchers may instead investigate the extent to which adjudicators at Irish dance competitions actively seek out athleticism, high kicks, or high hamstring flexibility in the dancers they judge. Despite the highly emphasized athleticism that Irish dance has seen in recent decades, the extent to which flexibility is important in comparison to more traditional aspects of Irish dance, such as rhythmic precision and proper posture, has not yet been investigated. The next step in research may be to determine whether modern aspects of Irish dance, particularly flexibility or high kicks, outweigh the more traditionally prominent components of an Irish dance performance in the eyes of certified Irish dance adjudicators. With such limited Irish dance research currently in existence, the potential opportunities for future research are endless. Based on this particular study, however, these topics may be worthy of investigation.

\section{Acknowledgements}

I would like to first express my appreciation to my 2018-2019 AP Research teacher, Mrs. Talarczyk, for guiding me throughout the process of study construction and providing valuable feedback to improve my work. I would also like to extend my thanks to the corresponding committees of the Pittsburgh Winter Feis and the North Coast Feis for permitting me to conduct data collection at these two events. My gratitude is also extended to my Irish dance instructor, Catherine Leneghan Fox, for allowing me to 
complete further data collection at her Thursday performance class. Finally, I wish to thank my parents for the encouragement that they provided throughout the course of this study.

\section{References}

Boland, R. A., \& Adams, R. D. (2000). Effects of Ankle Dorsiflexion on Range and Reliability of Straight Leg Raising. Australian Journal of Physiotherapy, 46(3), 191-200.

Cameron, D. M., \& Bohannon, R. W. (1993). Relationship Between Active Knee Extension and Active Straight Leg Raise Test Measurements. Journal of Orthopaedic \& Sports Physical Therapy, 17(5), 257-260.

Dancing Competition Rules. (2015). Retrieved from http://northamericanfeiscommission.org/uploads/2016_DANCING_COMPETITION_RU LES.pdf

Davis, D. S., Quinn, R. O., Whiteman, C. T., Williams, J. D., \& Young, C. R. (2008). Concurrent Validity of Four Clinical Tests Used to Measure Hamstring Flexibility. The Journal of Strength \& Conditioning Research, 22(2), 583-588.

Keay, N. (1998). Dancing Through Adolescence. British Journal of Sports Medicine, 32(3), 196.

Martinez, B. R., Curtolo, M., Lucato, A. C. S., \& Yi, L. C. (2014). Balance Control, Hamstring Flexibility and Range of Motion of the Hip Rotators in Ballet Dancers. European Journal of Physiotherapy, 16(4), 212218. https://doi.org/10.3109/21679169.2014.933485

Masero, A. (2010). The Changes in Irish Dance Since Riverdance. Honors College Capstone Experience/Thesis Projects. 234.

Mid-America Standardized Syllabus. (2017). Retrieved from https://midamericaregion.files.wordpress.com/2015/05/mid-america-syllabus-2017-ver_2.pdf

Mid-Atlantic Regional Syllabus. (2006). Retrieved from https://static1.squarespace.com/static/561c25f0e4b0982b2a58f408/t/588e887646c3c4023d8bdcbe/1485736055977/MA R+Syllabus+PAGE+1+Final+1.29.17.pdf

Noon, M., Hoch, A. Z., McNamara, L., \& Schimke, J. (2010). Injury Patterns in Female Irish Dancers. $P M \& R, 2(11), 1030-1034$.

One-Way ANOVA Calculator. (2019). Retrieved from https://www.socscistatistics.com/tests/anova/default2.aspx

Rules for Regional Councils. (1996). Retrieved from https://www.clrg.ie/images/RulesforRegionalCouncils.pdf

Russell, J. A. (2013). Preventing Dance Injuries: Current Perspectives. Open Access Journal of Sports Medicine, 4, 199.

Steffan, O. (2014). This Is How We Dance: The Impact of Riverdance on Irish Step Dancing. Drexel University. http://hdl.handle.net/1860/idea:6199

Stein, C. J., Tyson, K. D., Johnson, V. M., Popoli, D. M., d'Hemecourt, P. A., \& Micheli, L. J. (2013). Injuries in Irish dance. Journal of Dance Medicine \& Science, 17(4), 159-164.

Witvrouw, E., Danneels, L., Asselman, P., D'Have, T., \& Cambier, D. (2003). Muscle Flexibility as a Risk Factor for Developing Muscle Injuries in Male Professional Soccer Players: A Prospective Study. The American Journal of Sports Medicine, 31(1), 41-46. 
Appendix

\begin{tabular}{|c|c|c|c|c|c|c|c|}
\hline Dancer & Level & Age (years) & $\begin{array}{l}\text { Muscle injury in past } \\
6 \text { months? }\end{array}$ & $\begin{array}{l}\text { Amount of practice } \\
\text { days per week }\end{array}$ & $\begin{array}{l}\text { SLR } \\
\text { Angle: } \\
\text { Right }\end{array}$ & $\begin{array}{l}\text { SLR Angle: } \\
\text { Left }\end{array}$ & $\begin{array}{l}\text { SLR Angle: } \\
\text { Average }\end{array}$ \\
\hline 1 & $\mathrm{PC}$ & 9 & None & $5-6$ & 94 & 90 & 92 \\
\hline 2 & $\mathrm{PC}$ & 7 & None & 6 & 144 & 130 & 137 \\
\hline 3 & OC & 10 & None & 2 & 108 & 114 & 111 \\
\hline 4 & $\mathrm{OC}$ & 14 & None & 5 & 87 & 91 & 89 \\
\hline 5 & $\mathrm{OC}$ & 14 & None & 4 & 100 & 104 & 102 \\
\hline 6 & $\mathrm{PC}$ & 16 & None & $3-4$ & 105 & 109 & 107 \\
\hline 7 & $\mathrm{OC}$ & 13 & None & 6 & 113 & 113 & 113 \\
\hline 8 & PW & 15 & None & 1 & 89 & 80 & 84.5 \\
\hline 9 & PW & 8 & None & 3 & 90 & 93 & 91.5 \\
\hline 10 & $\mathrm{PC}$ & 14 & None & 2 & 118 & 113 & 115.5 \\
\hline 11 & $\mathrm{PC}$ & 12 & Yes: Shin splints & 4 & 128 & 130 & 129 \\
\hline 12 & $\mathrm{PC}$ & 16 & None & 3 & 122 & 117 & 119.5 \\
\hline 13 & $\mathrm{PC}$ & 13 & None & 2 & 92 & 86 & 89 \\
\hline 14 & $\mathrm{OC}$ & 16 & None & 6 & 136 & 131 & 133.5 \\
\hline 15 & $\mathrm{PC}$ & 14 & None & 4 & 125 & 108 & 116.5 \\
\hline 16 & $\mathrm{PC}$ & 14 & None & 4 & 121 & 124 & 122.5 \\
\hline 17 & OC & 17 & Yes: Pulled hip & 4 & 105 & 101 & 103 \\
\hline 18 & PW & 8 & None & $4-5$ & 115 & 114 & 114.5 \\
\hline 19 & PC & 10 & None & 7 & 113 & 115 & 114 \\
\hline 20 & $\mathrm{PC}$ & 10 & None & $5-6$ & 121 & 121 & 121 \\
\hline 21 & $\mathrm{PC}$ & 11 & None & 5 & 140 & 138 & 139 \\
\hline 22 & $\mathrm{PC}$ & 14 & None & $5-6$ & 132 & 114 & 123 \\
\hline 23 & $\mathrm{PC}$ & 12 & None & $5-6$ & 128 & 117 & 122.5 \\
\hline 24 & $\mathrm{PC}$ & 15 & None & $5-6$ & 144 & 133 & 138.5 \\
\hline 25 & $\mathrm{~N}$ & 7 & None & 5 & 115 & 110 & 112.5 \\
\hline 26 & $\mathrm{PC}$ & 12 & None & 4 & 111 & 101 & 106 \\
\hline 27 & $\mathrm{OC}$ & 21 & None & $4-5$ & 116 & Unknown ${ }^{\mathrm{a}}$ & 116 \\
\hline
\end{tabular}


Tournal of Student Research

AP Research (2019)

\begin{tabular}{|c|c|c|c|c|c|c|c|}
\hline 28 & $\mathrm{PC}$ & 9 & None & 3 & 146 & 132 & 139 \\
\hline 29 & $\mathrm{OC}$ & 19 & None & $4-6$ & 135 & 140 & 137.5 \\
\hline 30 & $\mathrm{OC}$ & 28 & None & $3-4$ & 117 & 116 & 116.5 \\
\hline 31 & $\mathrm{OC}$ & 23 & Yes: Pulled back & 3 & 107 & 103 & 105 \\
\hline 32 & $\mathrm{PC}$ & 9 & None & 4 & 131 & 129 & 130 \\
\hline 33 & $\mathrm{OC}$ & 18 & None & 4 & 139 & 126 & 132.5 \\
\hline 34 & $\mathrm{PC}$ & 16 & Yes: Pulled groin & $3-4$ & 142 & 135 & 138.5 \\
\hline 35 & PW & 9 & None & 3 & 112 & 131 & 121.5 \\
\hline 36 & PW & 10 & None & $3-4$ & 138 & 135 & 136.5 \\
\hline 37 & PW & 9 & None & $3-4$ & 108 & 124 & 116 \\
\hline 38 & $\mathrm{OC}$ & 13 & None & 3 & 136 & 120 & 128 \\
\hline 39 & $\mathrm{~N}$ & 12 & None & 1 & 77 & 70 & 73.5 \\
\hline 40 & PW & 9 & None & 2 & 113 & 96 & 104.5 \\
\hline 41 & PW & 38 & None & 2 & 100 & 103 & 101.5 \\
\hline 42 & $\mathrm{~N}$ & 11 & None & 1 & 106 & 108 & 107 \\
\hline 43 & $\mathrm{AB}$ & 10 & None & 1 & 111 & 102 & 106.5 \\
\hline 44 & PW & 22 & None & 2 & 100 & 110 & 105 \\
\hline 45 & PC & 11 & None & 6 & 152 & 149 & 150.5 \\
\hline 46 & $\mathrm{PC}$ & 11 & None & 6 & 156 & 148 & 152 \\
\hline 47 & $\mathrm{~N}$ & 11 & None & 3 & 95 & 99 & 97 \\
\hline 48 & $\mathrm{~N}$ & 12 & None & 5 & 157 & 127 & 142 \\
\hline 49 & PW & 13 & None & 3 & 99 & 93 & 96 \\
\hline 50 & $\mathrm{~N}$ & 10 & None & 3 & 115 & 114 & 114.5 \\
\hline 51 & $\mathrm{AB}$ & 9 & None & 5 & 115 & 106 & 110.5 \\
\hline 52 & PW & 11 & None & 4 & 96 & 84 & 90 \\
\hline 53 & $\mathrm{~N}$ & 12 & None & $3-4$ & 130 & 95 & 112.5 \\
\hline 54 & PW & 11 & None & 4 & 100 & 102 & 101 \\
\hline 55 & PW & 11 & None & 4 & 94 & 86 & 90 \\
\hline 56 & $\mathrm{~N}$ & 11 & None & 3 & 90 & 92 & 91 \\
\hline 57 & $\mathrm{AB}$ & 11 & None & 5 & 93 & 80 & 86.5 \\
\hline 58 & $\mathrm{~N}$ & 12 & None & $1-2$ & 114 & 101 & 107.5 \\
\hline
\end{tabular}


Journal of Student Research

AP Research (2019)

\begin{tabular}{llllllll}
59 & $\mathrm{~B}$ & 6 & None & $6-7$ & 114 & 106 & 110 \\
60 & $\mathrm{AB}$ & 6 & None & 2 & 104 & 99 & 101.5 \\
61 & $\mathrm{~N}$ & 8 & None & $6-7$ & 100 & 97 & 98.5 \\
\hline
\end{tabular}

Notes. OC: Open Championship

PC: Preliminary Championship

PW: Prizewinner

$\mathrm{N}$ : Novice

$\mathrm{AB}$ : Advanced Beginner

B: Beginner

aDancer 27 suffered from a knee injury at the time of data collection, leaving her unable to extend her left knee and properly complete the

SLR test. As a result, her data was eliminated from the results. 